\title{
Borrelia-like Spirochetes Recovered from Ticks and Small Mammals Collected in the Atlantic Forest Reserve, Cotia County, State of São Paulo, Brazil
}

\author{
IS Abel, G Marzagão, NH Yoshinari ${ }^{*}$, TTS Schumaker/ ${ }^{+}$
}

\begin{abstract}
Laboratório de Artropodologia, Departamento de Parasitologia, Instituto de Ciências Biomédicas, Universidade de São Paulo, Avenida Professor Lineu Prestes 1374, 05508-900 São Paulo, SP, Brasil *Laboratório Interação Microorganismo e Artrite, Departamento de Clínica Médica, Faculdade de Medicina, Universidade de São Paulo, Av. Dr. Arnaldo 455, 01246-903 São Paulo, SP, Brasil
\end{abstract}

Forty-four marsupials, 77 rodents and 161 ticks were captured in an Atlantic Forest Reserve in Cotia county, State of São Paulo, where human cases of Lyme disease $(L D)$ simile were reported. Twenty-one borrelia-like spirochete isolates were recovered from the mammals' blood and rodent livers or spleens, and triturated ticks inoculated into BSK II medium. Our results suggest that the reservoirs and ticks collected may harbor borrelia-like spirochetes, some of which have an antigenic similarity with the unknown causative agent of LD simile in Brazil, and/or with North American Borrelia burgdorferi s.s.

Key words: Ixodes spp.- wild mammals - borrelia-like spirochetes

Lyme disease (LD) is a multisystem human illness caused by the Borrelia burgdorferi sensu lato spirochete. It exists as zoonosis in the USA and Europe, and also occurs across temperate Asia and Australia (Gray 1998). This illness is transmitted to humans and other animals primarily by ticks of the Ixodes ricinus complex. However, this agent has also been detected and/or isolated from many other species of Ixodes which are not included in this complex, and several non-Ixodes species as well. In Brazil, human cases of LD simile, both clinical and serological, have been reported in the states of Rio de Janeiro, Amazonas, Mato Grosso do Sul and São Paulo (Yoshinari et al. 1997, 1999). However, attempts to isolate the agent have failed.

In Cotia county and vicinity, human cases compatible with LD and dogs with positive serological tests for this borreliosis have been recorded (Yoshinari et al. 1993, Joppert 1995). Thus, in order to isolate spirochetes from potential reservoirs and vectors, we captured rodents and marsupials in the Atlantic Forest Reserve (Morro Grande/

Supported by CNPq, Fapesp, and Capes.

${ }^{+}$Corresponding author. Fax: +55-11-818.7417. Email: ttsschum@icb.usp.br

Received 9 September 1999

Accepted 24 May 2000
Sabesp/ $23^{\circ} 36^{\prime} S ; 46^{\circ} 55^{\prime} \mathrm{W}$ ) Cotia county, and recovered ticks from them.

Trapping was carried out during five consecutive days of each month from August 1997 to July 1998. Animals were captured using traps baited with corn, for rodents $(n=30)$, and bacon for marsupials $(n=12)$. Marsupials were identified, labeled with a plastic collar, and after the blood collection by venepuncture, released at the site of capture. Blood samples were put into tubes containing BSK II medium for borreliae culture (Barbour 1984) and sera samples were kept at $-20^{\circ} \mathrm{C}$ until tested. Trapped rodents were brought to the laboratory, sacrificed and dissected aseptically. Samples of liver, spleen and blood were also inoculated into BSK II medium. Rodents were identified based on morphometric measurements and pelage coloration (Museu de Zoologia, Universidade de São Paulo, SP, Brazil). Genetic analysis was carried out when necessary. A protocol in agreement with that of the Ethical Principles in Animal Research, adopted by the Brazilian College of Animal Experimentation (Cobea), and approved by the Biomedical Sciences Institute/USP-Ethical Committee for Animal Research (CEEA) was used.

Ticks removed from each trapped animal were identified, washed with $3 \%$ oxygen peroxide and $70 \%$ alcohol, triturated, and inoculated into BSK II medium supplied with kanamycine $\left(3,6 \times 10^{-2}\right.$ $\mathrm{mg} / \mathrm{ml}$ ). All immature ticks, all non-engorged adult females and all adult males were triturated in pools 
of up to four ticks before inoculation. All engorged adult females were triturated and inoculated individually. Cultures were incubated at $33^{\circ} \mathrm{C}$ and examined periodically by dark-field microscopy.

In total, 1,680 live-trap nights produced 118 captures. The capture rate for each species was: marsupials - Philander opossum (21.2\%) and Didelphis, marsupialis (16.1\%); and rodents - Akodon montensis (22.9\%), Oligoryzomys nigripes (12.7\%), Thaptomys nigrita (11.9\%), Oryzomys russatus (10.2\%), Delomys sublineatus (4.2\%), Nectomys squamipes $(0.8 \%)$. The 161 ticks collected from opossums and rodents were Ixodes sp. larvae $(37.3 \%)$ and nymphs $(8.7 \%)$; I. loricatus adults (17.4\%) and I. didelphidis adults (22.4\%); Amblyomma sp. larvae (9.3\%), and nymphs (0.6\%), and Ornithodoros sp. larvae (4.3\%). The 113 ticks recovered from opossums only were I. loricatus adults $(24.8 \%)$ or I. didelphidis adults $(30.1 \%)$, Ixodes sp. larvae $(23 \%)$ or nymphs $(7.1 \%), \mathrm{Am}$ blyomma sp. larvae $(8 \%)$ or nymphs $(0.9 \%)$ and Ornithodoros sp. larvae (6.2\%). The 48 ticks collected from rodents were I. didelphidis adults (4.2\%), Ixodes sp. larvae $(70.8 \%)$ or nymphs (12.5\%) and Amblyomma sp. larvae (12.5\%).

Non motile Borrelia-like spirochetes were observed in 21 cultures after incubation periods that ranged from one week to six months. Positive cultures were obtained from marsupial blood $(n=6)$, rodent liver $(n=9)$, rodent blood $(n=1)$, and triturated ticks $(n=5)$. All of the five isolates obtained from ticks were recovered from Ixodes adults. Adult ticks generally show higher Borrelia-infection rate than immature ones, presumably because they have the chance to become infected at both the larval and nymphal stages (Gray 1998). Table I summarizes the number of captures, the number of animals that had tissues inoculated into BSK II medium, and the frequency of the infected animals. The $\mathrm{C}^{2}$ test was used to analyze the frequency of spirochetes among host species (Table II). Significance level was $p<0.05$. Among marsupials, $D$. marsupialis showed significantly higher infection rates than $P$. opossum $(p<0.05)$. With respect to other rodent, a few D. sublineatus or $N$. squamipes specimens were trapped to be included in our statistic analysis. We captured more A. montensis than any other rodent, and this species also showed a high infection rate. This species only differed significantly from $T$. nigrita $(p<0.05)$. Our data suggest that ticks of Ixodes species, rodents, and marsupials may be involved in the enzootic cycle of the present isolated borrelia-like spirochetes.

Three factors almost entirely eliminate the possibility of the presence of Spirochaetaceae other than the Borrelia species. First, Spirochaeta sp. microorganisms are free-living species, and thus require no host at all. Second, Brachyspira sp., Serpulina sp., and Critispira sp. are parasites of host species other than opossums or rodents. Third, Treponema sp. and Leptonema sp. do not grow in BSK II medium (Holt et al. 1994). One study does suggest that rodents and opossums can harbor Leptospira species which may occasionally be found simultaneously with Borrelia in this medium (Gorelova et al. 1996). However, our mammal sera were submitted to microscopic seroglutination assays to detect antibody to Leptospira sp., and, with the exception of one opossum serum ( $D$. marsupialis), all sera were negative. The spirochete isolates were tested by polymerase chain reaction using the primers Lep1 and Lep2 for genus Leptospira (Laboratórios de Zoonoses Bacterianas e de Biologia Molecular e Sorologia, Faculdade de

TABLE I

Borrelia-like spirochetes detected in rodents and opossums from Cotia county, State of São Paulo, Brazil

\begin{tabular}{lccl}
\hline Mammal species & Total captured & No. animals analyzed & $\begin{array}{c}\text { No. animals with } \\
\text { positive culture }(\%)\end{array}$ \\
\hline Marsupials & 19 (8 recaptured) & 11 & $4(36.4)$ \\
Didelphis marsupialis & 25 (5 recaptured) & 19 & $1(5)$ \\
Phylander opossum & & & $7(31.8)$ \\
Rodents & 27 & 22 & 0 \\
Akodon montensis & 5 & 5 & 0 \\
Delomys sublineatus & 1 & 1 & $2(14.3)$ \\
Nectomys squamipes & 15 & 14 & $1(9.1)$ \\
Oligoryzomys nigripes & 12 & 11 & $1(7.7)$ \\
Oryzomys russatus & 14 & 13 & 16 \\
Thaptomis nigrita & 118 & 96 & \\
\hline Total & & & \\
\hline
\end{tabular}

Culture tissues from mammals were inoculated into BSK medium and incubated at $33^{\circ} \mathrm{C}$. 
Medicina Veterinária e Zootecnia, Universidade de São Paulo, SP/Brasil), and the results were negative.

Thirteen spirochete isolates obtained from ticks, rodents or opossums were tested by indirect immunofluorescence assays (IFA). The reaction involved a polyclonal rabbit anti-B. burgdorferi serum, serum from the same rabbit prior to immunization (both provided by Dr Allen C Steere, MIT/ Boston, USA), sera of three researchers in the Departamento de Reumatologia (Faculdade de Medicina, USP) as normal human serum, and five sera of Brazilian patients with clinical signals and serology (ELISA and Western blotting) compatible with those of LD. These latter sera were previously tested for infectious diseases such as siphilis, leptospirosis, toxoplasmosis, hepatitis A, $\mathrm{B}$ and $\mathrm{C}$ and cytomegalovirus, as well as rheumatic diseases (all sera were provided by the Lyme Disease Reference Center in Brazil). Aliquot cultures were air-dried onto multiwell microscope slides and fixed for $10 \mathrm{~min}$ in cold acetone. For staining, slides were flooded with a 1:40 dilution of human sera or rabbit sera for $45 \mathrm{~min}$ at $37^{\circ} \mathrm{C}$. After being washed with PBS, each slide was flooded with a 1:40 dilution of FITC conjugated anti-rabbit IgG or antihuman $\mathrm{IgG}$, for $30 \mathrm{~min}$ at $37^{\circ} \mathrm{C}$. Slides were examined for fluorescence. Table III shows the reactivity of the 13-spirochete isolates to the LD Brazilian patients' sera or the polyclonal anti- $B$. burgdorferi rabbit serum. All control sera were negative. Results obtained by IFA suggest that the reservoirs and ticks collected in Cotia county can harbor borrelia-like spirochetes, some of which have an antigenic similarity with the unknown causative agent of LD simile in Brazil and/or North American B. burgdorferi s.s.

Usually, an incubation period of 1-4 weeks at $\gg 33^{\circ} \mathrm{C}$ is enough for the growth of B. burgdorferi s.l. in the BSK II medium (Barbour \& Hayes 1986). Our cultures required one week to three months (sometimes as much as six months) to present a non-motile microorganism that grew poorly in the medium used, a phenomenon also observed in iso-

\section{TABLE II}

Comparison of the proportion of infected mammals from Cotia county, State of São Paulo, Brazil

\begin{tabular}{|c|c|c|c|c|c|c|}
\hline Mammal species & $\begin{array}{c}\text { Didelphis } \\
\text { marsupialis }\end{array}$ & $\begin{array}{c}\text { Philander } \\
\text { opossum }\end{array}$ & $\begin{array}{c}\text { Akodon } \\
\text { montensis }\end{array}$ & $\begin{array}{c}\text { Oligoryzomyz } \\
\text { nigripes }\end{array}$ & $\begin{array}{c}\text { Oryzomys } \\
\text { russatus }\end{array}$ & $\begin{array}{c}\text { Thaptomys } \\
\text { nigrita }\end{array}$ \\
\hline D. marsupialis & - & 5.94 & 0.80 & 3.44 & 4.10 & 4,65 \\
\hline P. opossum & $p<0.05$ & - & 6.19 & 2.45 & 1.34 & 0.97 \\
\hline A. montensis & & $p<0.05$ & - & 3.17 & 3.91 & 4.57 \\
\hline O. nigripes & & & & - & 0.89 & 1.34 \\
\hline O. russatus & $p<0.05$ & & & & - & 0.39 \\
\hline T. nigrita & $p<0.05$ & & $p<0.05$ & & & - \\
\hline
\end{tabular}

The chi-squares values with one degree of freedom are shown on the upper diagonal while the significant levels are shown in the lower diagonal.

TABLE III

Borrelia-like spirochete indirect immunofluorescence reactions

\begin{tabular}{lcccccc}
\hline & \multicolumn{5}{c}{ Brazilian patient serum } \\
\cline { 2 - 7 } Isolate & $069 / 92$ & $073 / 92$ & $060 / 91$ & $717 / 95$ & $121 / 92$ & Rabbit $^{d}$ \\
\hline Ticks from SPM ${ }^{a}-5 r^{c}$ & - & + & - & - & - & + \\
Ticks from SPM-07r $c$ & - & + & - & + & - & + \\
Ticks from SPM-10 & - & - & - & - & - & - \\
SPM-13 & + & + & - & - & - & - \\
SPM-05r $c$ & - & - & - & - & - & + \\
SPM-09 & - & + & - & - & - & + \\
SPM-14 & - & - & + & - & - & - \\
SPR $b-51$ & - & - & - & - & - & - \\
SPR-55 & - & + & - & - & - \\
SPR-60 & - & + & - & - & - & - \\
SPR-64 & - & - & - & - & - \\
SPR-65 & - & - & + & - & - \\
SPR-74 & - & - & - & - & - \\
\hline
\end{tabular}

$a$ : marsupials; $b$ : rodents; $c$ : animal recaptured; (+) reactivity; (-) no reactivity; $d$ : rabbit serum immunized with inactivated Borrelia burgdorferi (dilution 1:40). 
lates recovered from ticks and mammals by other Brazilian researchers (Barros-Battesti 1998, Costa 1998). It is possible that Brazilian isolates require specific nutrients and may not be one of the $B$. burgdorferi genospecies already known.

Many aspects of the epidemiology of these spirochetes still remain to be investigated. The presence of the spirochetes in ticks or mammals does not prove their vector/reservoir competence. Experimental infection tests are needed to evaluate the ticks' ability to maintain and transmit such spirochetes to new hosts. Furthermore, the reservoir competence of a spirochete-infected mammal ought to be confirmed by xenodiagnosis tests.

As mixed cultures of spirochetes isolated from ticks or reservoirs have been recorded in other experiments (Rijpkema et al. 1996), our isolates might also include several Borrelia species, although demonstrating this would require further molecular tests.

\section{ACKNOWLEDGEMENTS}

To the Instituto Brasileiro do Meio Ambiente e dos Recursos Naturais Renováveis for permitting the capture of wild animals. To JR Nali for permitting the use of the Sabesp premises. To M Devivo for helping in the rodent taxonomy. To SA Vasconcellos and LJ Richtzenhain for the assistance in the Leptospira spp. investigations.

\section{REFERENCES}

Barbour AG 1984. Isolation and cultivation of Lyme disease spirochetes. Yale J Biol Med 57: 521-525.

Barbour AG, Hayes SF 1986. Biology of Borrelia species. Microbiol Rev 50: 381-400.

Barros-Battesti DM 1998. Estudos de Carrapatos e Pequenos Mamíferos Silvestres Naturalmente Infectados com Espiroquetas Semelhantes à Borre- lia no Município de Itapevi, Estado de São Paulo, PhD Thesis, Faculdade de Saúde Pública, Universidade de São Paulo, São Paulo, 142 pp.

Costa, IP 1998. Pesquisa de Anticorpos Anti Borrelia e do Agente Etiológico em Soro e Líquor de Pacientes com Manifestações Clínicas Compatíveis com a Doença de Lyme, no Estado de Mato Grosso do Sul, $\mathrm{PhD}$ Thesis, Faculdade de Medicina, Universidade de São Paulo, São Paulo, 125 pp.

Gorelova NB, Bellenger E, Postic D, Kovalevskii I 1996. Spontaneous mixed infection in rodents with Borrelia and Leptospira. Med Parazitol (Mosk) 4: 53.

Gray JS 1998. The ecology of ticks transmitting Lyme borreliosis. Exp Appl Acarol 22: 249-258.

Holt JG, Krieg NR, Sneath PHA, Staley JT, Williams AT 1994. The spirochetes. In DH Bergey, Bergey's Manual of Determinative Bacteriology, Williams and Wilkins, Baltimore, p. 27-37.

Joppert AM 1995. Estudo Soro-Epidemiológico da Infecção por Borrelia burgdorferi em Cães da Região de Cotia, São Paulo, MSc Thesis, Faculdade de Medicina Veterinária e Zootecnia, Universidade de São Paulo, São Paulo, 83 pp.

Rijpkema S, Golubic D, Molkenboer M, Verbek-De Kruif N, Schellekens J 1996. Identification of four genomic groups of Borrelia burgdorferi sensu lato in Ixodes ricinus ticks collected in a Lyme borreliosis endemic region of northern Croatia. Exp Appl Acarol 20: 23-30.

Yoshinari NH, Barros PJL, Stelling R, Baggio D, Yassuda P, Cossermelli W 1993. Epidemiological study of Lyme disease in Cotia. Rev Especial Reumatol 20 (Suppl.): 474.

Yoshinari NH, Barros PJL, Bonoldi VLN, Ishikawa MM, Barros-Battesti DM, Pirana S, Fonseca AH, Schumaker TTS 1997. Perfil da borreliose de Lyme no Brasil. Rev Hosp Clin Fac Med São Paulo 52: 111-117.

Yoshinari NH, Bonoldi VLN, Barros-Battesti DM, Schumaker TTS 1999. Doença de Lyme-símile no Brasil. Rev Bras Reumatol 39:1-2. 